\title{
Symptom resolution assessed using a patient directed diary card during treatment of acute exacerbations of chronic bronchitis
}

\author{
I S Woolhouse, S L Hill, R A Stockley
}

\begin{abstract}
Background-Acute exacerbations of chronic bronchitis are common and the presenting symptoms vary, although it is not clear how this should influence management. From a health care perspective, an understanding of the speed of symptom resolution is of importance to determine the success of treatment or when a change is indicated because of treatment failure. Methods-The response of 63 patients treated at home for exacerbations of chronic bronchitis was assessed using a patient directed diary card incorporating sputum characteristics and symptoms. Treatment was given according to the nature of the sputum at presentation; patients with purulent sputum received an antibiotic for 5 or 10 days (randomised, double blind) whereas patients with mucoid sputum received high dose inhaled steroid or placebo for 14 days (randomised, double blind).
\end{abstract}

Results-The mean (SE) total diary card score at presentation was significantly higher in the purulent group than in the mucoid group $(19.7(0.9) \quad v \quad 16.3(0.9)$; mean difference $-3.4(95 \% \mathrm{CI}-6.1$ to -0.7$)$, $\mathbf{p}<0.05)$. In the purulent group sputum colour and volume improved rapidly and in both groups the mean (SE) total diary card score had improved by the fifth day of treatment to $13.0(0.7)$ in the purulent group (mean difference -6.6 (95\% CI -8.8 to -4.4$), p<0.001)$ and $14.6(0.8)$ in the mucoid group (mean difference $-1.7(95 \%$ CI -4.0 to 0.8$), p<0.05)$, which was no longer significantly different from the stable state. Diary card scores did not differ significantly between patients who received antibiotics for 5 or 10 days in the purulent group or between patients who received inhaled fluticasone or placebo in the mucoid group.

Conclusions-Exacerbations of chronic bronchitis associated with purulent sputum have significantly worse symptoms at presentation than those with mucoid sputum. In both groups these symptoms resolve rapidly so that by the fifth day of treatment they are no different from the stable state. No significant effect was found on symptom resolution of antibiotic duration ( $5 v 10$ days) in the purulent group or of inhaled fluticasone in the mucoid group, which resolved without antibiotics. Larger numbers may be required to demonstrate a statistically (if not clinically) significant difference.

(Thorax 2001;56:947-953)

Keywords: chronic bronchitis; treatment; exacerbations; symptoms; diary card

Acute exacerbations of chronic bronchitis are a major health care burden in both primary and secondary care. Most patients with chronic bronchitis have 1-4 acute exacerbations per year which are usually defined on clinical grounds and most are treated at home. ${ }^{12}$ The management is usually empirical and often includes antibiotics and corticosteroids. Indeed, studies in chronic bronchitis and/or chronic obstructive pulmonary disease (COPD) have shown that both are effective ${ }^{3-5}$ but it remains unclear whether either or both are needed for individual patients. In addition, a decision to withhold treatment may result in failure of resolution of the exacerbation and repeated visits to health care professionals.

The symptoms of exacerbations vary but it is not clear how this influences management. In 1987 Anthonisen and colleagues published what remains the "gold standard" study of antibiotics versus placebo for acute exacerbations of COPD. ${ }^{6}$ The authors stratified the patients according to the appearance or increase of $1-3$ of the major symptoms (sputum purulence, sputum volume, and dyspnoea). Overall the study showed a significant advantage of antibiotic treatment in symptom resolution, although $\chi^{2}$ analysis of the data indicates that antibiotics probably influenced resolution significantly only in the group where all three symptoms were increased $(\mathrm{p}<0.01)$.

Data on the time course of symptom resolution and the effect of treatment and its duration for acute exacerbations are limited. In one study of patients with moderate to severe COPD the median time for recovery from an acute exacerbation in the community was 7 days. ${ }^{7}$ However, patients only indicated the presence, not the severity, of their daily respiratory symptoms and, for the $50 \%$ of the exacerbations that were identified retrospectively, treatment was not standardised. In another study of antibiotic treatment of exacerbations in patients with COPD and asthma in general practice the mean symptom severity score decreased by 0.05 units a day. ${ }^{8}$ However, only $27 \%$ of patients in the study produced mucopurulent or purulent sputum during the
2 August 2001

Accepted for publication

2 August 2001 
exacerbation and resolution of sputum volume and purulence was not assessed.

Health status has been measured more formally in a preliminary study of a small number of patients following antibiotic treatment for acute exacerbations of COPD using the activity and impact components of the $\mathrm{St}$ George's Respiratory Questionnaire (SGRQ). ${ }^{9}$ Changes in the scores of these components appeared to follow two phases-a rapid improvement over the first week followed by a longer period of several weeks before a plateau was reached. Sputum colour, as assessed by the patients, improved over 2 weeks but sputum volume remained unchanged. However, this study has yet to be published in full.

Although questionnaires such as the SGRQ provide useful information on health status, they are not generally suitable for completion by the patient on a daily basis. To assess the time course of recovery from acute exacerbations of chronic lung disease a simpler tool is therefore required. In the 1980s we developed a diary card (incorporating sputum characteristics and symptoms) that was successfully used by patients with bronchiectasis to document changes in clinical status and differentiate between response and non-response to antibiotic treatment. ${ }^{10} 11$

The aim of the present study was to use a modification of this diary card to assess the time course of symptom resolution in a large group of patients with chronic bronchitis treated in the community for an acute exacerbation. We compared the resolution of exacerbations with purulent sputum at presentation with those where the sputum was mucoid. We also assessed the effect of 5 or 10 days of treatment with antibiotics in the former and inhaled fluticasone or placebo in the latter.

\section{Methods}

Patients aged 40-80 years with a history of chronic bronchitis, as defined by daily sputum production for at least 3 months of 2 consecutive years, ${ }^{12}$ were recruited to the study when they presented to their primary care physician with an acute exacerbation. The exacerbation was characterised and included one or more of increased dyspnoea, increased sputum volume and a change in purulence, with or without the presence or worsening of other symptoms (cough, increased sputum viscosity, wheeze, chest pain, malaise, and fever). For ethical reasons patients who, in the view of their primary care physician, required oral corticosteroids or admission to hospital were excluded.

Treatment of the exacerbation was determined according to the nature of the sputum at presentation. It was felt to be ethically unjustified to withhold an antibiotic from patients presenting with (muco)purulent sputum, so they were randomised to receive oral cefuroxime axetil $500 \mathrm{mg}$ twice daily for 5 or 10 days in a double blind manner. Patients who presented with mucoid sputum received inhaled fluticasone propionate $500 \mu \mathrm{g}$ twice daily or placebo for 14 days (randomised, double blind). The sputum and microbiological features have been reported elsewhere. ${ }^{13}{ }^{14}$

Diary cards were given to patients when they presented with the exacerbation (day 1) and were explained in full by a respiratory research nurse before initiation of treatment. The following were recorded daily from presentation to the end of treatment and into the stable clinical state: (a) dyspnoea graded from 0 (excellent) to 4 (bad), (b) general wellbeing from 0 (excellent) to 4 (bad), (c) cough from 1 (occasionally) to 3 (persistently), (d) sputum consistency from 1 (watery) to 4 (solid), (e) sputum purulence from 1 (colourless), 2 (putty colour) and 3 to 5 (increasing yellow or green colour) using an integrated colour chart, (f) sputum volume from 0 (none) to 3 (cupful or more), (g) daytime symptoms - that is, the impact of respiratory symptoms on ability to work or perform normal daily activities - from 0 (none) to 4 (unable to work or perform normal daily activities) and (h) night time symptoms - that is, the impact of respiratory symptoms on sleep disturbance-from 0 (none) to 4 (no sleep at all). In addition, the best of three peak expiratory flow measurements was recorded both morning and night before inhaled treatment using a Wright's mini peak flow meter for the duration of the study.

Patients were reviewed on the 5th day of treatment (day 5), at the end of the treatment period (day 10 for purulent and day 14 for mucoid exacerbations), and when clinically stable (approximately 8 weeks after the initial presentation). At each review the study nurse checked diary card completion.

When seen in the stable clinical state, high resolution CT scanning (1 $\mathrm{mm}$ slices) was performed and assessed as described previously ${ }^{15}$ to determine the presence of bronchiectasis using accepted criteria. ${ }^{16}$ In addition, dynamic lung volumes and vital capacity were measured using a wedge bellows spirometer (Vitalograph, Buckinghamshire, UK). Short acting bronchodilators were omitted for 6 hours before spirometric measurements and long acting bronchodilators for 12 hours. The best of three satisfactory traces agreeing within $50 \mathrm{ml}$ for forced expiratory volume in 1 second $\left(\mathrm{FEV}_{1}\right)$ and $150 \mathrm{ml}$ for forced vital capacity (FVC) were accepted for analysis. The measurements were repeated 20 minutes after inhalation of $400 \mu \mathrm{g}$ salbutamol to determine the presence and degree of any reversibility of airflow obstruction.

The study was approved by the South Birmingham Health Authority ethics committee and all subjects provided written informed consent.

DIARY CARD ANALYSIS

The score given by the patient to each item for the diary card was used in the analysis. In addition, a total diary card score was obtained by adding together all of the individual scores. Data from patients not stable when reviewed 2 months after the exacerbation were excluded, otherwise all available data was analysed. 
Table 1 Details of patients withdrawn from the study

\begin{tabular}{|c|c|c|c|c|}
\hline \multirow[b]{2}{*}{ Reason for withdrawal } & \multicolumn{2}{|c|}{ Purulent exacerbations } & \multicolumn{2}{|c|}{ Mucoid exacerbations } \\
\hline & $\begin{array}{l}5 \text { days } \\
\text { cefuroxime }\end{array}$ & $\begin{array}{l}10 \text { days } \\
\text { cefuroxime }\end{array}$ & Fluticasone & Placebo \\
\hline Non-resolution of presenting symptoms & 1 & 0 & 1 & 2 \\
\hline Further exacerbation & 6 & 4 & 4 & 1 \\
\hline Unwilling to continue & 0 & 1 & 0 & 0 \\
\hline Total withdrawals & 7 & 5 & 5 & 3 \\
\hline
\end{tabular}

Table 2 Patient characteristics

\begin{tabular}{|c|c|c|c|c|}
\hline \multirow[b]{2}{*}{ Demographic data } & \multicolumn{2}{|c|}{ Purulent exacerbations } & \multicolumn{2}{|c|}{ Mucoid exacerbations } \\
\hline & $\begin{array}{l}5 \text { days } \\
\text { cefuroxime }\end{array}$ & $\begin{array}{l}10 \text { days } \\
\text { cefuroxime }\end{array}$ & Fluticasone & Placebo \\
\hline Age & $66.1(8.0)$ & $65.9(10.3)$ & $65.2(6.5)$ & $59.5(8.9)$ \\
\hline $\mathrm{M} / \mathrm{F}$ & $12 / 9$ & $13 / 6$ & $6 / 7$ & $6 / 4$ \\
\hline Current(ex) smokers & $9(12)$ & $8(11)$ & $8(5)$ & $8(2)$ \\
\hline $\mathrm{FEV}_{1}$ pre bronchodilator (\% predicted) & $55.3(19.6)$ & $67.4(27.5)$ & $63.8(28.3)$ & $70.0(22.0)$ \\
\hline $\mathrm{FEV}_{1} / \mathrm{VC}$ pre bronchodilator $(\%)$ & $46.6(14.7)$ & $56.8(17.6)$ & $51.0(18.9)$ & $56.8(18.9)$ \\
\hline Increase in $\mathrm{FEV}_{1}$ after salbutamol (l) & $0.15(0.14)$ & $0.19(0.13)$ & $0.19(0.13)$ & $0.17(0.12)$ \\
\hline
\end{tabular}

Values are mean (SD).

There were no significant differences between any of the subgroups studied.

\section{STATISTICAL ANALYSIS}

All statistical analyses were performed using the sPss statistical package (version 8.0, Chicago, USA). Age and $\mathrm{FEV}_{1}$ are expressed as mean (SD), and the patient groups were compared using a one way analysis of variance (ANOVA). $\chi^{2}$ or Fisher's exact tests were used to compare categorical data between groups.

For statistical analysis of the diary card data we used day 1 (presentation), day 5, day 10 and/or 14 (end of treatment), and day 56 (stable clinical state) as appropriate summary measures. The Mann-Whitney test was used to compare differences between sputum and treatment groups and the Wilcoxon signed rank test was used to compare data at presentation and on day 5, at the end of treatment, and the stable clinical state. The level of statistical significance was taken as $<0.05$.

\section{Results}

Diary cards were collected from 111 patients who presented with an acute exacerbation of their lung disease and $93(84 \%)$ contained sufficient data for analysis. High resolution CT scanning performed in the stable clinical state

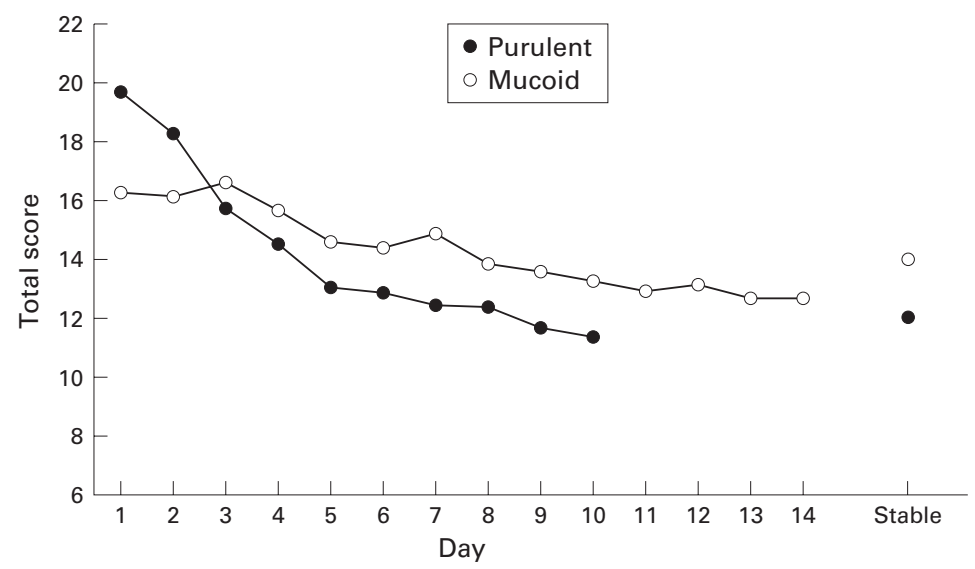

Figure 1 Mean total diary card scores for days 1 (presentation) to 10 (purulent group) and 14 (mucoid group) as well as in the stable clinical state. revealed evidence of bronchiectasis (usually mild tubular change) in 30 patients and these patients were excluded from further analysis. In the remaining 63 patients the sputum was purulent at presentation in 40 (referred to as the purulent group) and mucoid in 23 (referred to as the mucoid group). Twenty one patients in the purulent group received cefuroxime for 5 days and 19 received treatment for 10 days. In the mucoid group 13 patients received inhaled fluticasone propionate and 10 received inhaled placebo (each for 14 days).

Details of the patients withdrawn from the study are shown in table 1 . Withdrawal rates were similar for all treatment groups. The four patients who were withdrawn for nonresolution of presenting symptoms all received prednisolone (from day 6 to day 10 onwards). They continued to record their symptoms using the diary card and their scores were included in the analysis up to the end of the treatment period; however, stable state diary card data were not available from these patients. Fifteen patients had a further exacerbation after the end of the treatment period. Their presentation, day 5 , and end of treatment diary card scores for the first episode were included in the analysis. In addition, 11 of these patients were able to provide diary card data when they were clinically stable (seven in the purulent group, four in the mucoid group) and this was also included.

PATIENT CHARACTERISTICS

The characteristics of the patients are summarised in table 2 . There was no significant difference between either group and most $(77 \%)$ had airflow obstruction $\left(\mathrm{FEV}_{1} / \mathrm{VC}<70 \%\right)$; $27 \%$ of the patients had significant reversibility $\left(>200 \mathrm{ml}\right.$ and $>15 \%$ increase in $\mathrm{FEV}_{1}$ over baseline) following treatment with $\beta_{2}$ agonist although the mean increase in $\mathrm{FEV}_{1}$ was small (table 2). There was no significant difference in the number of patients in the mucoid group who were on inhaled corticosteroids before entry into the study (seven in the fluticasone arm and five in the placebo arm).

DIARY CARD SYMPTOMS

The mean (SE) total diary card score at presentation was significantly higher in the purulent group than the mucoid group (19.7 (0.9) $v 16.3$ (0.9); mean difference -3.4 (95\% CI -6.1 to -0.7$), \mathrm{p}<0.05)$. However, this difference mainly reflected the sputum purulence score which (by definition) was higher in this group (3.6 (0.2) $v 1.9$ (0.2); mean difference -1.7 (95\% CI -2.2 to -1.2$)$, $\mathrm{p}<0.001)$. In the stable state mean (SE) total scores were similar between the two groups (purulent 12.0 (1.0) $v$ mucoid 14.0 (0.9); mean difference 2.0 (95\% CI -0.9 to 4.8 ), $\mathrm{p}=\mathrm{NS}$ ) and significantly lower than at presentation (fig 1).

Of the major symptoms (as defined by Anthonisen et $a l^{6}$ ), the dyspnoea score alone was higher in the mucoid group at presentation (2.8 (0.1)) than in the stable state $(2.2(0.2)$; mean difference -0.6 ( $95 \%$ CI -1.0 to -0.2$)$, 

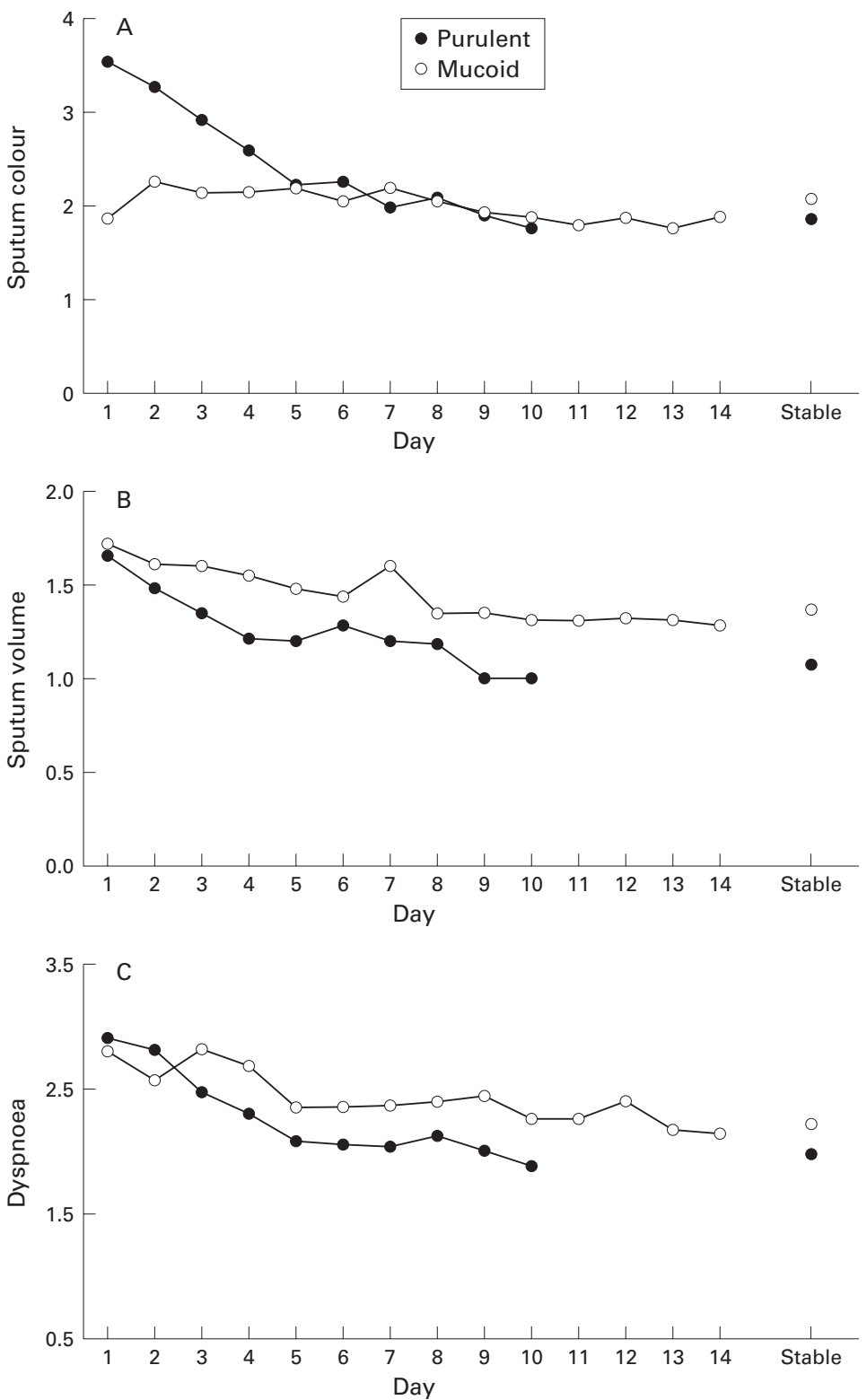

Figure 2 (A) Mean sputum colour score, (B) sputum volume score, and (C) dyspnoea score for days 1 (presentation) to 10 (purulent group) and 14 (mucoid group) as well as in the stable clinical state.
Symptom resolution

In the purulent group the diary card scores for sputum colour and volume improved rapidly from presentation to mean (SE) scores at day 5 of $2.2(0.2)$ for colour (mean difference -1.3 (95\% CI -1.8 to -0.8$), \mathrm{p}<0.001)$ and $1.2(0.1)$ for volume (mean difference -0.5 (95\% CI -0.8 to -0.1$), p<0.01)$. These values were no longer different from the subsequent stable state scores with a mean difference of $0.4(95 \%$ CI -0.1 to 0.9 ) for colour and 0.1 (95\% CI -0.2 to 0.4 ) for volume. No change was seen in either of these symptoms in the group who presented with mucoid sputum (fig $2 \mathrm{~A}$ and $\mathrm{B}$ ).

By day 5 dyspnoea scores (fig 2C) had fallen in both groups to mean (SE) scores of $2.1(0.1)$ in the purulent group (mean difference -0.8 $(95 \% \mathrm{CI}-1.1$ to -0.5$), \mathrm{p}<0.01)$ and $2.3(0.1)$ in the mucoid group (mean difference -0.5 $(95 \% \mathrm{CI}-0.9$ to -0.1$), \mathrm{p}<0.05)$. These values were no longer different from the stable state scores with a mean difference of 0.1 (95\% CI -0.2 to 0.4 ) for the purulent group and 0.1 (95\% CI -0.3 to 0.6 ) for the mucoid group.

The mean (SE) total diary card score (fig 1) had improved by day 5 of treatment to 13.0 (0.7) in the purulent group (mean difference $-6.6(95 \% \mathrm{CI}-8.8$ to -4.4$), \mathrm{p}<0.001)$ and to $14.6(0.8)$ in the mucoid group (mean difference -1.7 (95\% CI -4.0 to 0.8$), \mathrm{p}<0.05)$. There was a further improvement by the end of treatment to $11.4(0.6)$ in the purulent group (mean difference -1.7 (95\% CI -3.5 to 0.2 ), $\mathrm{p}=0.001)$ and to $12.7(0.9)$ in the mucoid group (mean difference -1.9 (95\% CI -4.2 to $0.4), \mathrm{p}<0.01)$. Neither the scores on day 5 or at the end of treatment were significantly different from those seen in the stable state.

\section{Effect of treatment type and duration}

The total diary card, dyspnoea, sputum purulence, and volume scores at presentation, on day 5, at the end of treatment, and in the stable clinical state did not differ significantly between patients who received antibiotics for 5 or 10 days in the purulent group, nor between patients who received inhaled fluticasone or placebo in the mucoid group (table 3 ).

$\mathrm{p}<0.05$ ), whereas in the purulent group the scores were significantly higher at presentation than in the stable state for all three symptoms: sputum colour (3.6 (0.2) v 1.9 (0.2); mean difference -1.7 ( $95 \% \mathrm{CI}-2.2$ to -1.2$), \mathrm{p}<0.001)$, sputum volume $(1.7$ (0.1) v 1.1 (0.1); mean difference $-0.6(95 \%$ CI -0.9 to -0.3$)$, $\mathrm{p}<0.001)$, and dyspnoea (2.9 (0.1) v $2.0(0.1)$; mean difference -0.9 ( $95 \%$ CI -1.3 to -0.6 ), $\mathrm{p}<0.001$; fig 2).

The score for general wellbeing was $2.4(0.1)$ in the mucoid group at presentation and did not change significantly when seen in the stable state $(2.1$ (0.2); mean difference -0.3 (95\% CI -0.8 to 0.2$), p=N S$ ). However, a clear change in the wellbeing score was seen in the group who presented with purulent sputum from 2.8 $(0.1)$ at presentation to $1.9(0.1)$ in the stable state (mean difference -0.8 (95\% CI -1.2 to $-0.5), \mathrm{p}<0.001)$.

\section{PEAK EXPIRATORY FLOW MEASUREMENTS}

Mean (SE) PEF measurements in the morning (PEFam) and evening (PEFpm) at presentation did not differ significantly between the purulent and mucoid groups (PEFam: 248 (19) $1 / \mathrm{min} v 277$ (23) $1 / \mathrm{min}$; mean difference $30 \mathrm{l} / \mathrm{min}$ (95\% CI -30 to 89 ), PEFpm: 259 (20) $1 / \mathrm{min} v 293$ (22) $1 / \mathrm{min}$; mean difference $34 \mathrm{l} / \mathrm{min}$ (95\% CI -29 to 98$)$ ). By the end of treatment both morning and evening PEF measurements had significantly improved in the purulent group (PEFam by 31 (9) $1 / \mathrm{min}$ ( $95 \%$ CI 13 to 50 ), p<0.05 and PEFpm by 28 (10) $1 / \mathrm{min}$ (95\% CI 7 to 49$)$. In the mucoid group PEFam improved by 25 (7) $1 / \mathrm{min}(95 \%$ CI 10 to 40 ), $p<0.05$, but the improvement in PEFpm of 11 (10) 1/min (95\% CI -9 to 32) did not reach statistical significance $(p=0.128)$. The improvements in PEF measurements did not differ between treatment groups. 


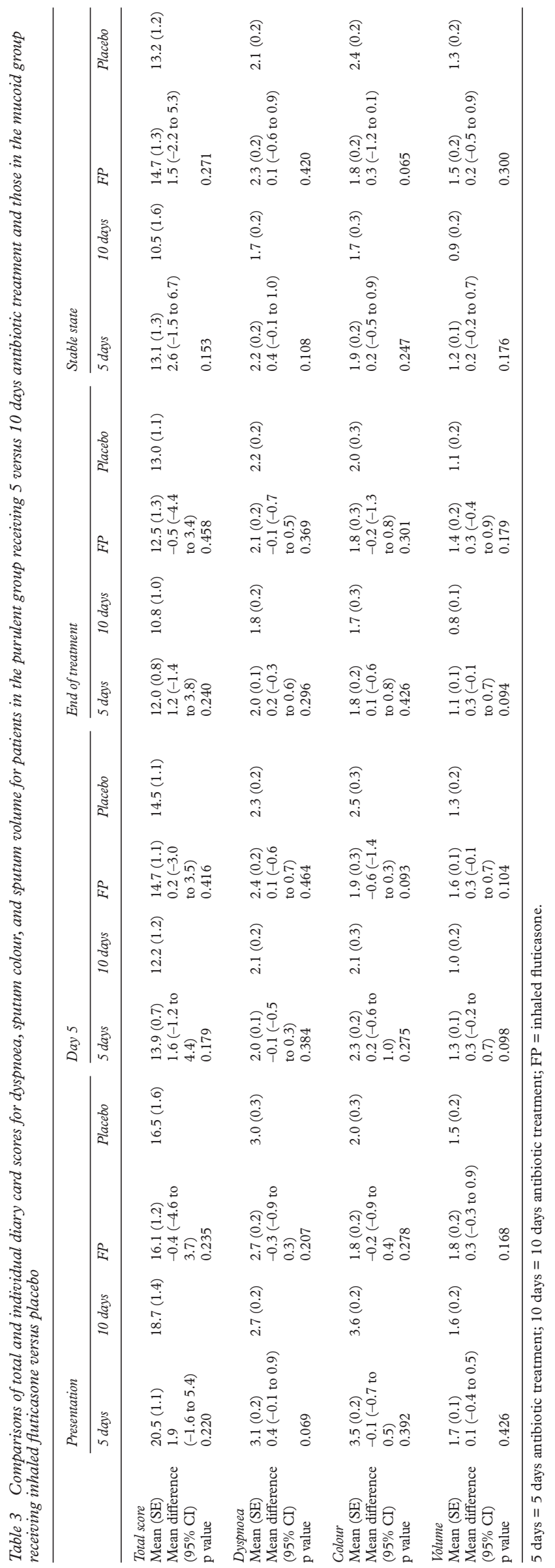

\section{Discussion}

We have used a patient directed diary card to assess the resolution of symptoms in patients with exacerbations of chronic bronchitis treated according to the nature of the sputum at presentation. The exacerbations were characterised (according to Anthonisen's criteria ${ }^{6}$ ) to include one or more of increased dyspnoea, sputum purulence, and sputum volume. In addition, to ensure a homogenous study population, data from patients with evidence of bronchiectasis on high resolution CT scanning were excluded from the analysis. Although it could be argued that, in routine clinical practice the exclusion of minor bronchiectasis is not important before treating exacerbations of chronic bronchitis, we have previously reported that the radiological severity of bronchiectasis detected in this group of patients can include both cystic and varicose disease $\mathrm{e}^{15}$ which may influence the outcome of the acute exacerbation, although this requires further study.

At presentation of the exacerbation we found that patients with purulent sputum had a significantly worse total diary card score than those with mucoid sputum. This was predominantly due to the sputum colour score; however, this group also noticed an increase in both sputum volume and dyspnoea whereas only one of Anthonisen's major features (dyspnoea) was increased in patients with mucoid sputum. In addition, the purulent group felt significantly less well at presentation than in the stable state (wellbeing score), although patients with mucoid sputum did not. This finding is consistent with the increase in C reactive protein levels which was seen in patients presenting with purulent sputum, ${ }^{14}$ indicating a systemic response to the acute episode in this group. Taking these data together would therefore suggest that the major reason for the mucoid group seeking medical help was increased breathlessness with little evidence of systemic illness, whereas patients with purulent sputum have more symptoms and are more systemically unwell.

The symptoms and PEF of patients with purulent sputum at presentation improved rapidly, returning to the stable state by the fifth day of treatment. It was considered unethical to withhold antibiotic treatment from patients with sputum that was clearly purulent and thus it was not possible to determine whether symptom resolution in this group was influenced by antibiotics alone. However, the speed of improvement of sputum colour, in particular, suggests a positive effect and the data suggest that it may be possible to address spontaneous resolution in future studies using the diary card, with early rescue treatment if resolution of sputum purulence is delayed or symptoms worsen.

The symptoms in patients with mucoid sputum at presentation resolved without antibiotics. Given that the predominant symptom in this group was dyspnoea, treatment could be aimed at ameliorating this symptom alone, perhaps with bronchodilator therapy. Indeed, studies have shown that long acting $\beta_{2}$ agonists 
can reduce exacerbations in $\mathrm{COPD}^{17}$ and it may be this subset of patients with increased dyspnoea who benefit from such treatment alone. The improvement in PEF as the episode resolved in these patients would suggest a physiological basis for this rationale.

We were not able to show any significant difference in symptom resolution between patients who received antibiotics for 5 or 10 days in the purulent group or between patients who received inhaled fluticasone or placebo in the mucoid group. This finding needs to be interpreted with some caution. Given the relatively small numbers in each treatment group, it is possible that the power of the study might not have been sufficient to detect small yet statistically significant differences in diary card scores. We were unable to perform power calculations before the study as there are no previous data available on the expected variability using this diary card in this group of patients. However, post hoc power analysis showed that 21 patients in the 5 day antibiotic treatment arm and 19 in the 10 day arm were sufficient to demonstrate a difference in total diary card score of 4.0 and an individual score of 0.7 with $80 \%$ power. Similarly, 13 patients in the fluticasone arm and 10 patients in the placebo arm were sufficient to detect a difference in the total diary card score of 4.7 and an individual score of 0.9 with $80 \%$ power. In clinical terms the ability to detect a difference of 1 in sputum colour score equates to a change from frankly purulent to mucopurulent and, similarly, with dyspnoea a difference of 1 detects a change from "usual" to "worse than usual" breathlessness. Clearly, to demonstrate smaller statistically significant differences in diary card scores requires more patients in each treatment group, but the clinical significance of such small changes in symptoms is uncertain.

Empirical guidelines for the management of acute exacerbations of chronic bronchitis and/or COPD in the community recommend antibiotic treatment for between 7 and 14 days. ${ }^{2} 1819$ Our results suggest, that in uncomplicated outpatient exacerbations, treatment with antibiotics for 10 days is unlikely to effect a major change in symptom resolution compared with treatment for 5 days. It has been suggested that the time to and number of subsequent exacerbations following completion of treatment are also important outcome measures. ${ }^{3}$ The incidence of recurrent exacerbations 6 weeks after completion of treatment in our study did not differ significantly between patients receiving treatment for 5 or 10 days (table 1), which provides further support for the use of 5 days of treatment in patients similar to those described here.

The effect of inhaled fluticasone in patients with mucoid sputum at presentation may have been underestimated in this study by the exclusion of patients who, in the view of their general practitioner, required oral corticosteroids. This was undertaken for ethical reasons but, given the beneficial effect of inhaled corticosteroids on the number and severity of COPD exacerbations ${ }^{20}{ }^{21}$ and oral corticosteroids in more severe exacerbations requiring hospital admission, ${ }^{22}{ }^{23}$ the effect of inhaled steroids on symptom resolution during exacerbations of chronic bronchitis may be worthy of further study and the diary card may again facilitate early rescue strategies.

In summary, we have used a patient directed diary card to assess symptom resolution in a large group of patients treated in the community for an exacerbation of chronic bronchitis. Patients presenting with purulent sputum had significantly worse symptoms at presentation, both in terms of number and severity, than patients with mucoid sputum. However, in both groups these symptoms resolved rapidly so that by day 5 of treatment they were back to stable state levels. We were not able to detect a significant effect on symptom resolution of antibiotic duration (5 $v 10$ days) in the purulent group or of inhaled fluticasone in mucoid group which resolved without antibiotics. However, the numbers in each group were small and larger groups may be required to demonstrate statistically (if not clinically important) differences. These data could provide the background for prospective placebo controlled studies with early rescue treatment if required.

The authors acknowledge B Leung, $\mathrm{M}$ Henson, and $\mathrm{K}$ Verbeet (respiratory research nurses) for their hard work in collecting data during this study.

Funding: Unrestricted educational grant from GlaxoWellcome. Conflict of interest: none.

1 Ball P, Harris JM, Lowson D, et al. Acute infective exacerbations of chronic bronchitis. Q F Med 1995;88:61-8.

2 COPD Guidelines Group of the Standards of Care Committee of the BTS. BTS guidelines for the management of chronic obstructive pulmonary disease. Thorax 1997;52(Suppl 5):S1-28.

3 Ball P. Epidemiology and treatment of chronic bronchitis and its exacerbations. Chest 1995;108:43-52S.

4 Saint S, Bent S, Vittinghoff E, et al. Antibiotics in chronic obstructive pulmonary disease exacerbations. A metaanalysis. $\mathcal{F A M A}$ 1995;273:957-60.

5 Thompson WH, Nielson CP, Carvalho P, et al. Controlled trial of oral prednisone in outpatients with acute COPD exacerbation. Am 7 Respir Crit Care Med 1996;154:407-12.

6 Anthonisen NR, Manfreda J, Warren CP, et al. Antibiotic therapy in exacerbations of chronic obstructive pulmonary therapy in exacerbations of chronic obstruct

7 Seemungal TA, Donaldson GC, Bhowmik A, et al. Time course and recovery of exacerbations in patients with chronic obstructive pulmonary disease. Am $\mathcal{F}$ Respir Crit Care Med 2000;161:1608-13

8 Sachs AP, Koeter GH, Groenier KH, et al. Changes in symptoms, peak expiratory flow, and sputum flora during treatment with antibiotics of exacerbations in patients with chronic obstructive pulmonary disease in general practice. Thorax 1995;50:758-63.

9 Annie K, Lowton K, Jones PW. Changes is health status following an acute infective exacerbation of COPD. Eur Respir f 1997;10:148s.

10 Hill SL, Morrison HM, Burnett D, et al. Short term response of patients with bronchiectasis to treatment with amoxycillin given in standard or high doses orally or by inhalation. Thorax 1986;41:559-65.

11 Hill SL, Burnett D, Hewetson KA, et al. The response of patients with purulent bronchiectasis to antibiotics for four patients with purulent bronchiectasis
months. $O \mathcal{F}$ Med $1988 ; 66: 163-73$.

12 Definition and classification of chronic bronchitis for clinical and epidemiological purposes. A report to the Medical Research Council by their Committee on the Aetiology of Chronic Bronchitis. Lancet 1965;i:775-9.

13 Stockley RA, Bayley D, Hill SL, et al. Assessment of airway neutrophils by sputum colour: correlation with airways inflammation. Thorax 2001;56:366-72.

14 Stockley RA, O'Brien C, Pye A, et al. Relationship of sputum color to nature and outpatient management of
acute exacerbations of COPD. Chest 2000;117:1638-45.

15 O'Brien C, Guest PJ, Hill SL, et al. Physiological and radiological characterisation of patients diagnosed with chronic obstructive pulmonary disease in primary care. Thorax 2000;55:635-42.

16 Naidich DP, McCauley DI, Khouri NF, et al. Computed tomography of bronchiectasis. F Comput Assist Tomogr $1982 ; 6: 437-44$ 
17 Mahler DA, Donohue JF, Barbee RA, et al. Efficacy of salmeterol xinafoate in the treatment of COPD. Chest 1999;115. 957-65.

18 Chodosh S. Treatment of acute exacerbations of chronic bronchitis: state of the art. Am F Med 1991;91:87-92S.

19 Siafakas NM, Vermeire P, Pride NB, et al. Optimal assessment and management of chronic obstructive pulmonary disease (COPD). The European Respiratory Society Task Force. Eur Respir f 1995;8:1398-420.

20 Burge PS, Calverley PM, Jones PW, et al. Randomised, double blind, placebo controlled study of fluticasone propionate in patients with moderate to severe chronic obstructive pulmonary disease: the ISOLDE trial. BMF 2000;320: $1297-303$
21 Paggiaro PL, Dahle R, Bakran I, et al. Multicentre randomised placebo-controlled trial of inhaled fluticasone propionate in patients with chronic obstructive pulmonary disease. International COPD Study Group. Lancet 1998;

22 Davies L, Angus RM, Calverley PM. Oral corticosteroids in patients admitted to hospital with exacerbations of chronic obstructive pulmonary disease: a prospective randomised controlled trial. Lancet 1999;354:456-60.

23 Niewoehner DE, Erbland ML, Deupree RH, et al. Effect of systemic glucocorticoids on exacerbations of chronic obstructive pulmonary disease. Department of Veterans Affairs Cooperative Study Group. N Engl F Med 1999;340: $1941-7$

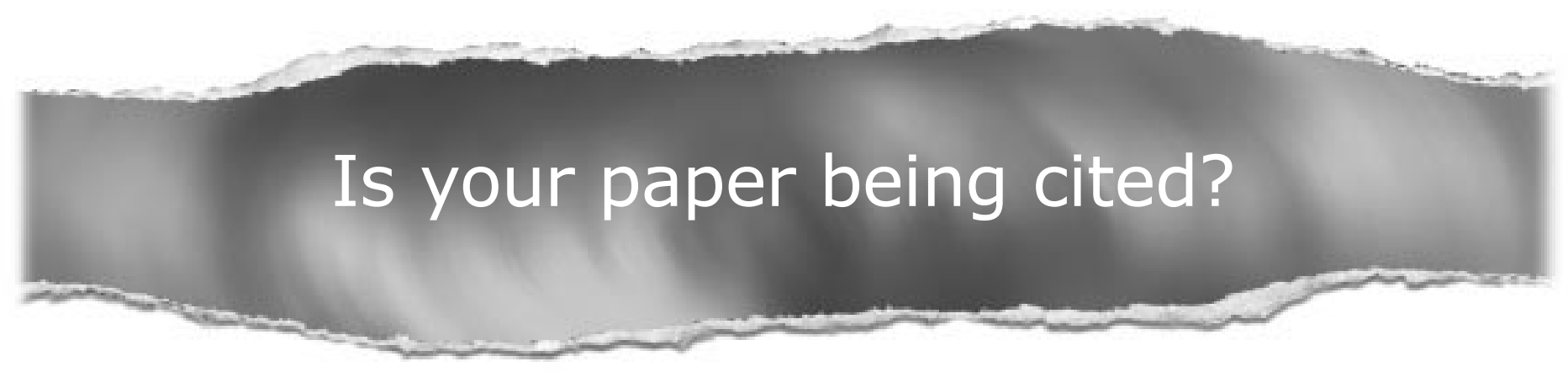

CiteTrack service

CiteTrack will alert you by email whenever new content in Thorax or a participating journal is published that matches criteria you want to track

Topics: Tell CiteTrack which words or subjects to watch for in new content Authors: Be alerted whenever key authors you are following publish a new paper Articles: Know whenever a paper of interest to you is referenced by another paper

\section{www.thoraxjnl.com}

